\title{
Medication Adherence to Oral Hypoglycemic Agents Among Type II Diabetic Patients and Their Clinical Outcomes with Special Reference to Fasting Blood Glucose and Glycosylated Hemoglobin Levels Shrestha SS, ${ }^{1}$ Shakya $\mathrm{R},{ }^{3}$ Karmacharya BM, ${ }^{2}$ Thapa $\mathrm{P}^{3}$
}

\author{
${ }^{1}$ Department of Pharmacology \\ ${ }^{2}$ Department of Community Medicine \\ Dhulikhel Hospital-Kathmandu University Hospital \\ Kathmandu University School of Medical Sciences \\ Dhulikhel, Kavre, Nepal \\ ${ }^{3}$ Department of Pharmacy \\ School of Science Kathmandu University
}

\author{
Corresponding Author \\ Sony Shakya Shrestha \\ Department of Pharmacology \\ Dhulikhel Hospital-Kathmandu University Hospital \\ Kathmandu University School of Medical Sciences \\ Dhulikhel, Kavre, Nepal \\ E-mail: sonyshakya@hotmail.com
}

\section{Citation}

Shrestha SS, Shakya R, Karmacharya BM, Thapa P. Medication Adherence to Oral Hypoglycemic Agents Among Type II Diabetic Patients and Their Clinical Outcomes with Special Reference to Fasting Blood Glucose and Glycosylated Hemoglobin Levels. Kathmandu Univ Med J 2013;43(3):226-232.

\section{ABSTRACT \\ Background}

Oral hypoglycemic agents (OHAs) are the major treatment for people with type 2 diabetes mellitus (DM2). However, non-adherence to OHAs remains as one of the main reasons for poor glycemic control.

\section{Objectives}

To assess the adherence pattern to OHAs and clinical outcomes with special reference to fasting blood glucose (FBG) level and glycosylated hemoglobin (HbA1c) levels.

\section{Methods}

Informed consent was obtained from patients fulfilling the criteria and from the patient party in case of incapacitated patients. Information was obtained by interviewing them and filled in the appropriate questionnaire. All the medical information of the patients was obtained from the medical case records and laboratory reports.

\section{Results}

OHAs had been discontinued by $25 \%$ of patients. Overall $38 \%$ had ever discontinued and/ or often missed OHAs. Intentional discontinuation of OHAs attributed for $72 \%$ of the patients, followed by forgetfulness $(42.9 \%)$, carelessness $(30.6 \%)$, and hypoglycemia, (24\%). There were $50.50 \%$ patients who had uncontrolled FBG (>130 $\mathrm{mg} / \mathrm{dl}$ ) level and $39 \%$ had uncontrolled HbA1c ( $\geq 7 \%$ ) level. Taking reference age group 51-60 years, control of FBG level was found to be statistically associated with the decreasing age group $(p=0.006, O R=4.8)$ as well as increasing age group ( $p$ $=0.008, \mathrm{OR}=4.034$ ). There was significant association between controlled $\mathrm{HbA} 1 \mathrm{c}$ level and patients' knowledge about the precautions to be taken while using $\mathrm{OHAs}$ $(p=0.044, O R=4)$. However, there was no significant association between glycemic control and $\mathrm{OHAs}$ adherence.

\section{Conclusion}

Majority of the patients who had missed OHAs attributed it to forgetfulness. Hypoglycemia may also be one of the contributing factors for poor adherence to OHAs. However no association was found between adherence and various other factors like age groups, treatment complexity, health literacy and social or family support.

\section{KEY WORDS}

Adherence, diabetes, HbA1c, hypoglycemia, non-adherence 


\section{INTRODUCTION}

Diabetes mellitus, especially type-2 diabetes mellitus (DM2) is a major global health problem covering approximately 347 million persons worldwide. ${ }^{1}$ It is predicted that the global prevalence of diabetes will increase by $65 \%$ over the next 20 years. ${ }^{2}$ In Bir hospital, diabetes was reported to be the fifth leading cause of mortality. ${ }^{3}$

Oral hypoglycemic agents (OHAs) are the major treatment for DM2 patients and these agents are targeted for intensive blood-glucose control which leads to a decrease in microvascular complications, such as nephropathy and retinopathy. ${ }^{4}$ However, non-adherence to OHAs remains as one of the main reasons for poor glycemic control. ${ }^{5}$ Patients' self-reports can simply and effectively measure adherence. ${ }^{6}$ Problems with poor self-management of drug therapy may exacerbate the burden of diabetes. ${ }^{7}$ To improve patient adherence, it is important to understand why non-adherence occurs. Commonly proposed reasons for non-adherence to oral medication regimens include forgetfulness and spontaneous activities due to a lack of self-discipline, limited intelligence, or fearless attitude towards the consequences of diabetes. ${ }^{8,9}$ Only $37.7 \%$ of the patients treated with $\mathrm{OHAs}$ have glycosylated hemoglobin (HbA1c) $<7 \% .{ }^{10}$ Once the prescription is written, however, the fate of drug therapy is with the patient. For such chronic medical conditions, a wide and persistent separation exists between evidence-based recommendations and the actual care patients receive. Reasons for this gap are not always clear, however, lack of persistence with adherence to prescribed treatments is a critical part of the gap. ${ }^{11}$

To date, data about the patient adherence to OHAs in Nepal is not available. As Nepal is one of the developing countries, there is a need for patient education incorporating information about disease complications, their prevention and management. Therefore this study attempted to address some issues regarding adherence and clinical outcomes in our setting.

\section{METHODS}

This observational cross-sectional study has been approved by the Institutional Review Committee, Kathmandu University School of Medical Sciences (IRC/ KUSMS) and the study was conducted at Dhulikhel Hospital, Kathmandu University Hospital, Dhulikhel. All DM2 patients on at least one OHAs for at least one month, who came to medical OPD/ lab/ emergency department / admitted in ward satisfying inclusion criteria were taken and fasting blood glucose (FBG) test was done and when feasible post prandial blood glucose test was also carried out. Besides these tests, HbA1c test in fasting condition was also done for those subjects who had not had HbA1c test for previous 3 months. Regarding the major factors affecting adherence to OHAs, emphasis was given to awareness of the patients, age, ethnicity, literacy, their personal habit, identification of the OHAs including dose regimen among other drugs being used by them, duration of use of OHAs, knowledge about the side-effects of OHAs, awareness about the precautions and other measures to be undertaken by the patient while using OHAs, the reason for taking the OHAs regularly, knowledge of the diabetic complications and benefit of regular blood test and physician visit. All the information were then filled in data collection form.

One hundred consecutive patients who were already diagnosed as DM2 and were on at least one OHA were included in this study. The inclusion criteria are: a) all the patients attending lab or OPD or the emergency department or those who were admitted in the ward who were taking OHAs at the time of data collection and b) the patients who, at some point of time had started taking OHAs but discontinued the medicines on their own in spite of the medical recommendations to continue the drugs. Statistical analysis was performed by applying Chi-square test using Statistical Package for Social Sciences (SPSS) Version 17. P-value $<0.05$ was considered as significant.

\section{RESULTS}

Out of 100 patients, there was almost equal number of female $(n=52)$ and male patients $(n=48)$. Mean (S.D) age of the patients was 58.1 years $( \pm 11.6)$. The median FBG level among 95 patients was $132 \mathrm{mg} / \mathrm{dl}$ (72-390 mg/dl). However, mean $\mathrm{HbA} 1 \mathrm{c}$ level among 41 patients was within the normal range as per ADA i.e., 6.8\%. Equal numbers of the patients were using single and two OHAs (41 each) and majority of them $(n=36)$ were using Biguanides together with Sulfonylureas respectively as shown in fig 1 .

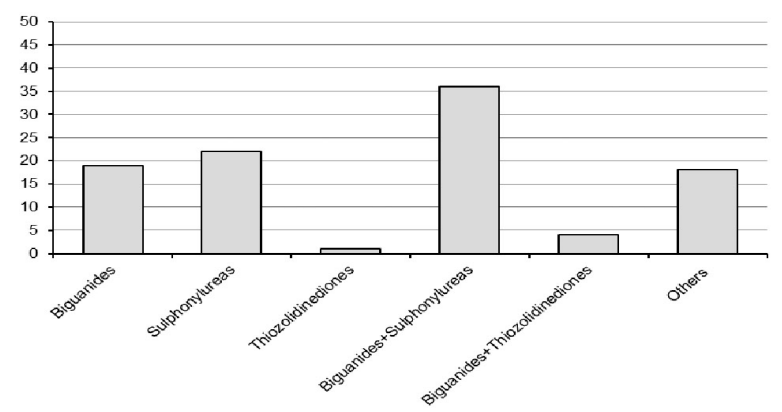

Figure 1. Different OHAs used by 100 patients.

Regarding adherence pattern, a total of 25 patients (25\%) had ever discontinued OHAs and about half of the patients ( $n=49$ ) mentioned of having missed OHAs for at least one dose. Overall $38 \%$ of the patients were not adherent to their OHAs. The details of the adherence pattern to OHAs are shown in table 1.

The Kaplan Meier analysis of the patients who discontinued the OHAs revealed that by 231 months $( \pm 23)$ of the initiation of OHAs, half of the patients will have discontinued the medicine at some point of time.

The knowledge of the DM2 patients regarding drugs and 
Table 1. Adherence pattern among 100 patients.

\begin{tabular}{|lcc|}
\hline \multicolumn{1}{c}{ Characteristics } & No. of Patients & Percentage \\
\hline $\begin{array}{l}\text { Patients who had ever discontin- } \\
\text { ued OHAs }\end{array}$ & 25 & 25 \\
\hline \begin{tabular}{l} 
Time of discontinuing (Month after its initiation ) \\
\hline $1-6$
\end{tabular} & 8 & 32 \\
\hline $7-12$ & 1 & 4 \\
\hline $13-18$ & 1 & 4 \\
\hline $19-24$ & 3 & 12 \\
\hline $43-48$ & 1 & 4 \\
\hline $55-60$ & 3 & 12 \\
\hline$\geq 61$ & 8 & 32 \\
\hline
\end{tabular}

Median (Range ) time of discontinuationof $\mathrm{OHAs}$ (month after initiation) : month (1-204)

Reason of discontinuation of OHAs $(n=25)$

Self ${ }^{\dagger}$

Side effects $^{\mp}$
Financial problem

Patients who missed OHAs (ex-

cluding ones who discontinued)

Missing frequency $(n=49)$

$\begin{array}{lll}\text { Rarely } & 29 & 59.2 \\ \text { Often } & 20 & 40.8\end{array}$

Reason for missing OHAs ( $n=49)$

\begin{tabular}{lcc} 
Forgetfulness & 21 & 42.9 \\
Carelessness & 15 & 30.6 \\
Financial problem & 3 & 6.1 \\
Meal irregularities & 4 & 8.1 \\
\hline Forget +Carelessness & 2 & 4 \\
Others \$ & 4 & 8.2
\end{tabular}

${ }^{t}$ Reason of discontinuation of OHAs intentionally as see fit, thinking that the drug is not helping in improving current symptoms and/ or due to asymptomatic conditions and/or with fear of long term use.

${ }^{\mp}$ The patients who discontinued OHAs in the study were found only due to hypoglycemia

$\$$ Due to combinations of forgetfulness/ carelessness/ financial problem/ meal irregularities

disease is shown in fig 2 in which significant number of the patients were unaware of the side effect, hypoglycemia.

There was no significant association of adherence with the age, sex, education, occupation, Body mass index (BMI), number of OHAs being taken, duration of use of $\mathrm{OHAs}$, drug missing frequency, recognition of OHAs, experience of hypoglycemia, knowledge about the timing of dose regimen, consequences of irregular therapy, precautions, practice of other measures to control blood glucose level and family/ social support.

No significant association of adherence and adherence related factors with glycemic control was found except the significant association ( $p=0.006)$ between age groups and fasting blood glucose level; and patients' knowledge about precautions to be taken while using $\mathrm{OHAs}$ and $\mathrm{HbA} 1 \mathrm{c}$ level $(p=0.044)$. The odds of having controlled FBG level are 4.8

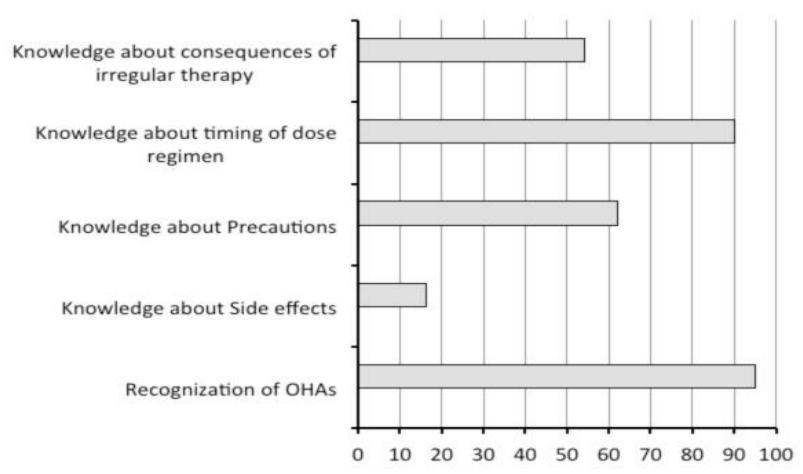

Figure 2. Patients' knowledge about DM and OHAs.

and 4.034 times greater among the patients of age group 51-60 years than among the patients of age group 30-50 years and $61-90$ years respectively. Similarly, the odds ratio of controlled $\mathrm{HbA} 1 \mathrm{c}$ is 4 for the patients who have knowledge about the precautions to be taken while using OHAs as shown in table 2.

\section{DISCUSSION}

Frequently, in medicine, compliance and adherence are used as interchangeable terminology and they are being tried to paid attention. However, adherence to medications is not routinely measured in clinical practice, and a gold standard that can be easily implemented, even for research purpose, does not exist. For this study, patients were considered to be adherent if they had never discontinued and/ or never or rarely missed OHAs. ${ }^{12}$ This study used the questionnaires, which is one of the indirect methods of measurement of adherence. . $^{13,14}$

In this study, 25\% were found to have ever discontinued OHAs. The Kaplan Meier analysis of the patients who discontinued the OHAs revealed that by 231 months of the initiation of OHAs, half of the patients will have discontinued the medicine. Similarly another study had found that patients with DM2 averaged only about 130 days per year of continuous drug therapy; at the end of one year, only $15 \%$ of patients who had been prescribed a single OHA were still taking it regularly. ${ }^{15}$ In another aspect, 20 patients (41\%) were found to have missed their OHAs often. There were total of 38 patients (38\%) who were found to be non adherent to OHAs. Consistent with these findings, previous surveys had found that people took approximately $75 \%$ of medications as prescribed, across a variety of medical disorders. ${ }^{6}$ These results also correspond to the findings from a study done by Diabetes Attitudes, Wishes and Need (DAWN) in 13 countries in which about $20 \%$ of the respondents (DM2) said that they did not fully follow medication recommendation. ${ }^{7}$

This study shows that the maximum number of the patients who had ever discontinued the drugs did so in the first 6 months and after 60 months of initiation of treatment. One of the studies have found the similar result that there was the highest chance of missing the drugs in 
Table 2. Demographic and other characteristics of 95 patients with regards to short term glycemic control (Fasting Blood Glucose level) and long term glycemic control (HbA1c).

\begin{tabular}{|c|c|c|c|c|c|c|c|c|}
\hline Variables & Total (n) & $\begin{array}{c}\text { Controlled } \\
\text { FBG }^{+}(n=47) \\
\text { No.(\%) }\end{array}$ & $\begin{array}{c}\text { Uncontrolled } \\
\text { FBG }^{\mp}(n=48) \\
\text { No.(\%) }\end{array}$ & $p$ - value & Total (n) & $\begin{array}{l}\text { Controlled } \\
\text { HbA1c } \\
(n=25) \text { No.(\%) }\end{array}$ & $\begin{array}{c}\text { Uncontrolled } \\
\text { Hba1c* }(n=16) \\
\text { No.(\%) }\end{array}$ & $p$-value \\
\hline \multicolumn{9}{|l|}{ Age (years) } \\
\hline $30-40$ & 8 & $4(50)$ & $4(50)$ & $0.006^{a}$ & 4 & $2(50)$ & $2(40)$ & $0.739^{b}$ \\
\hline $41-50$ & 19 & $6(31.6)$ & $13(68.4)$ & & 7 & $5(71.4)$ & $2(28.6)$ & \\
\hline $51-60$ & 27 & $20(74.1)$ & $7(25.9)$ & & 15 & $10(66.7)$ & $5(33.3)$ & \\
\hline $61-70$ & 33 & $16(48.5)$ & 17.(51.5) & & 14 & $8(57.1)$ & $6(42.9)$ & \\
\hline $71-80$ & 7 & $0(0)$ & $7(100)$ & & 1 & $0(0)$ & $1(100)$ & \\
\hline $81-90$ & 1 & $1(100)$ & $0(0)$ & & & & & \\
\hline $51-60$ & 27 & 20 & 7 & $0.006(\mathrm{OR}=4.8)$ & & & & \\
\hline $30-50$ & 27 & 10 & 17 & Ref: 51-60 & & & & \\
\hline $51-60$ & 27 & 20 & 7 & $0.008(\mathrm{OR}=4.034)$ & & & & \\
\hline $61-90$ & 41 & 17 & 24 & Ref:51-60) & & & & \\
\hline \multicolumn{9}{|l|}{ Education } \\
\hline Illiterate & 44 & 26.(59.1) & $18(40.9)$ & 0.082 & 17 & $8(47.1)$ & $9(52.9)$ & 0.124 \\
\hline Literate & 51 & $21(21.2)$ & $30.58 .8)$ & & 24 & $17(70.8)$ & $7(29.2)$ & \\
\hline \multicolumn{9}{|c|}{ Number of OHAs } \\
\hline Single drug & 40 & $23(57.5)$ & $17(42.5)$ & 0.233 & 16 & $11(68.8)$ & $5(31.2)$ & $0.414^{c}$ \\
\hline Two drugs & 37 & $18(48.6)$ & $19(51.4)$ & & 17 & $7(41.2)$ & 10.(8.8) & \\
\hline$>2$ drugs & 18 & $6(33.3)$ & $12(66.7)$ & & 8 & $7(87.5)$ & $1(12.5)$ & \\
\hline $\begin{array}{l}\text { Non-adher- } \\
\text { ence }\end{array}$ & 36 & $18(50)$ & $18(50)$ & 0.936 & 22 & $13(59.1)$ & $9(40.9)$ & 0.79 \\
\hline Adherence & 54 & $29(49.2)$ & $30(50.8)$ & & 19 & $12(63.2)$ & $7(36.8)$ & \\
\hline \multicolumn{9}{|c|}{ Knowledge about Precaution } \\
\hline Yes & 62 & $31(50)$ & $31(50)$ & 0.888 & 28 & $20(71.4)$ & $8(28.6)$ & $0.044(\mathrm{OR}=4$ \\
\hline No & 33 & $16(48.5)$ & $17(51.5)$ & & 13 & $5(38.5)$ & $8(61.5)$ & Ref:No \\
\hline $\begin{array}{l}\text { + Patients who } \\
\text { F Patients who } \\
\text { \$ Patients who } \\
\text { * Patients who } \\
\text { a Age groups } \\
\text { b Age groups } \\
\text { c Two drugs ar }\end{array}$ & $\begin{array}{l}\text { FBG level c } \\
\text { FBG level i } \\
\text { HbA1c leve } \\
\text { HbA1c leve } \\
30-40 \text { and } \\
30-40 \text { and } \\
\text { two drug }\end{array}$ & $\begin{array}{l}\text { plies with the tr } \\
130 \mathrm{mg} / \mathrm{dl} \\
\text { omplies with th } \\
\geq 7 \% \\
50 \text { ) years and ( } 7 \\
50 \text { ) years and ( } 6 \\
\text { ere pooled }\end{array}$ & $\begin{array}{l}\text { atment goal by } \\
\text { treatment goal } \\
-80 \text { and } 81-90) \\
-70 \text { and } 71-80)\end{array}$ & $\begin{array}{l}\text { DA i.e., } \leq 130 \mathrm{mg} / \mathrm{dl} \\
\text { iven by ADA i.e., } \\
\text { ears were pooled } \\
\text { ears were pooled }\end{array}$ & & & & \\
\hline
\end{tabular}

the first six months of treatment and another study had found that adherence decreases over time. ${ }^{8,16}$ So, similar pattern was found in this study, however, statistically, no relationship was found between the duration of use of $\mathrm{OHAs}$ and patients' medication adherence. Patients might discontinue or often miss OHAs at any time after their initiation. It might be because the treatment regimen (both drugs and dose regimen) might have possibility of being modified (addition of new drug or removal of drugs that are being taken or change of dose regimen) over the course of the disease in order to limit the blood glucose level to optimum. ${ }^{17}$ Hence such modification could make the patient difficult to adopt in most of the time. They might get difficulty in managing the dose regimen with their lifestyle or might not have formed habit. It might also be possible that the patient might think that they were not getting any benefit from their medications or might feel asymptomatic or get fade up from their use and do not feel their importance as suggested by previous study which had stated that lower regimen adherence can be expected when a health condition is chronic, when the course of symptoms varies or when symptoms are not apparent, when a regimen is more complex, and when a treatment regimen requires lifestyle changes. ${ }^{5}$

It has been shown that the patients might sometimes notice immediate positive benefits when blood glucose levels were lowered, but many patients might not feel these changes, and some might become aware of only negative consequences like hypoglycemia. ${ }^{18}$ It might be the reason due to which maximum of the patients who had ever discontinued OHAs, in this study, were found to discontinue the OHAs by themselves intentionally. The 
finding is also consistent with the finding from previous study, which had reported that the intentional reasons for non-adherence were reported more frequently than unintentional. ${ }^{19}$

In this study, only 16 patients were found to have knowledge about hypoglycemia as side effect of the OHAs. So this might be the reason that $24 \%$ who had ever discontinued $\mathrm{OHAs}$, were found to be due to the side effects of the OHAs (mainly hypoglycemia). Supporting this result, other study has highlighted that the side effect that may contribute to levels of poor adherence is hypoglycemia, which had led to hypoglycemia being labeled as the main barrier to the effective management of diabetes mellitus. ${ }^{18,20}$ Hence, special attention should be paid in continuous counseling of diabetic patients throughout their lifetime for a better compliance. They should be made aware that DM2 is a chronic disease and their medicines were helping them to live healthier and longer life; the treatment would not succeed if they do not take part in their therapy. One of the studies had also stated that adherence to a course of therapy is more likely when a patient understands the reasons for taking a medication and is involved in the decision to prescribe. Patients are more likely to have confidence in the prescriber if they are given basic knowledge of potential adverse effects and advice about what to do if such effects occur. ${ }^{21}$

Recent evidence has suggested that as many as onequarter of patients with diabetes may be suffering with a moderate to major depressive disorder and depression may often go undiagnosed and/ or untreated. ${ }^{22}$ Needless to say, depression may contribute to problematic use of medications, due to increase in forgetfulness and/ or a loss of interest in protecting one's health. ${ }^{23}$ This might be the reason that in this study, $42.9 \%$ of the patients used to miss OHAs due to forgetfulness followed by $30.6 \%$ patients missing OHAs due to their carelessness about their health conditions. The result obtained is consistent with the finding from the previous study which had reported that, in response to questionnaire, the patients who claimed to be fully adherent, highlighted forgetfulness as the central reason for not taking their medications. ${ }^{14,24}$

Although no patient in this study was diagnosed to be suffering from depressive illness, it cannot be totally ruled out because the patients had not had psychiatric consultation. The DAWN study has shown that a significant number of diabetic patients have poor psychological well being and that the providers reported that these psychological problems adversely affected regimen adherence. ${ }^{25}$

While relating demographic and other characteristics with the adherence, no significant results were obtained. Studies have shown that better adherence was found with simpler regimens than with more complex ones. In this study no such significant difference was found among the single drug users, two drug users and more than two drug users. They were almost equally adhered to their OHAs regimen. These results are found to be different from the result obtained from two previous reviews, in which they have reported that when the patients are taking multiple OHAs, compliance level falls. ${ }^{26,27}$ It might be due to the small sample size. However, another study done by Grant et al in DM patients has determined that a higher number of prescribed medicines were not associated with poorer per-medicine adherence. ${ }^{28}$ Rather patient with suboptimal adherence tend to have problems with one specific medicine, either because of unreported side effects or because the patient feels that medicines are not of value to current or future health. So continuous patient education and awareness program are required. It shows the emergence of more detailed patient assessment regarding their medication adherence.

Optimal glycemic control remains elusive for many diabetic patients despite the recent introduction of several new OHAs. So this study had attempted to relate different factors with short term and long term glycemic control. Statistically significant association was found between age and FBG level $(p=0.006)$. The odds of having controlled FBG level are 4.8 and 4.034 times greater among the patients of age group 51-60 years than among the patients of age group 30-50 years and 61-90 years respectively. This result is partially consistent with the result obtained in previous study done in Hawaii, which had found that younger diabetic patients had the poorest glycemic control and worst health outcomes. ${ }^{29}$ The authors of that study had proposed that a possible explanation for better adherence among the older patients is that they are more knowledgeable and experienced with using the medications. However, with increasing age and burden of disease, adherence becomes more difficult to maintain over time due to which glycemic control becomes difficult to achieve too. ${ }^{14}$

No statistical association was found between glycemic control (short term and long term) and demographic and other factors. Some part of this result is consistent with the result obtained from previous study in which the researchers have found that there was no association between metabolic control and gender, encounter frequency, frequency of $\mathrm{HbA} 1 \mathrm{c}$ testing or continuity of care. $^{30}$ Regarding the OHAs treatment, no significant difference was observed in the glycemic control from either the single drug or two drugs or more than two drugs. Probably it is true that use of more medications is not associated with better glycemic control. Similar kind of result was obtained in another study which also emphasizes that more oral medications, rather is a marker for a greater likelihood of poor control. ${ }^{31}$ Only by increasing the number of medicines might not improve glycemic control. There are various confounding factors that have effect on the glycemic control. The success of therapy largely depends on the responsibility of patients. With the growing evidence of the strong link between health status and behaviour, it is becoming clearer that many chronic diseases such as 
diabetes are best viewed as behaviour disorders as stated by Jenny (1986). ${ }^{17}$ Therefore, patients' behaviour might be one of the confounding factors that might affect in showing the association between treatment regimen and glycemic control.

Medication adherence also has no significant relationship with the glycemic control. Patients who had ever discontinued or often missed OHAs and those who had never discontinued and/ or never or rarely missed OHAs had similar kind of outcomes. It might be because it is an observational study. The time gap between the discontinued days and the blood glucose tested day might not be related due to which their association was not exhibited in this study. The literature also provides conflicting results with regard to the importance of medication adherence on health outcomes. While most of these studies have shown that non adherence to medications is associated with worse outcomes in chronic diseases including diabetes in agreement with present findings, other a studies have found weak correlation or no association between patient adherence to treatment regimen and metabolic control (HbA1c). ${ }^{32-36}$ Such contrasting results might be due to the involvement of a relatively small patient population and lack of follow- up period. Nevertheless, the relationship between medication adherence and health outcomes cannot be overruled in the present scenario. So this study addresses the need of further prospective studies to explore more about the association of glycemic control and medication adherence.

A significant association was found between the patients' knowledge about precautions to be taken while using $\mathrm{OHAs}$ and long term glycemic control. The finding emphasizes for including such measures when monitoring management, for emphasizing the importance of such behaviours in programs of both provider and patient education, and for developing strategies that support these particular features of patient self-management.

\section{CONCLUSION}

Adherence problems are common in diabetes management. Diabetes, a chronic disease, though requires the behavioral changes with adequate knowledge and change in attitude, still a significant number of patients are unaware about the various important aspects of their OHAs like side effects, precautions and the disease itself like its consequences and complications. Significant number of the patients had ever discontinued the $\mathrm{OHAs}$ by themselves intentionally as see fit, thinking that the drug is not helping in improving current symptoms and/ or due to asymptomatic conditions and/ or with fear of long-term use. This study also adds to the general finding that side effect that may contribute to level of poor adherence is hypoglycemia. In another aspect, maximum of the patients who had missed OHAs showed the reason of forgetfulness, which is commonly present in chronic diseases like diabetes.
This study shares several limitations mainly due to the absence of a 'gold standard' measure of adherence. The study being retrospective and mono-centered involving limited sample size, the real influence of various parameters with regards to adherence and clinical outcomes (FBG and $\mathrm{HbA1c}$ ) could have been missed. However, this study definitely provides various important issues related to adherence pattern and the clinical outcomes with special reference to FBG and $\mathrm{HbA} 1 \mathrm{c}$ levels.

Identifying and overcoming medication compliance is challenging, but worth the time and effort. Practitioners should always look for poor adherence and can enhance adherence by emphasizing the value of a patients' regimen, making the regimen simple, and customizing the regimen to the patient's lifestyle. Asking patients non-judgmentally about medication taking behavior can be a practical strategy for identifying poor adherence. Multifaceted interventions that incorporate structural and counseling components and include appropriately skilled and motivated pharmacists appear useful to promote medication adherence. Patients who have difficulty maintaining adequate adherence need more intensive strategies than do patients who have less difficulty with adherence. Innovative methods of managing chronic diseases like diabetes may have some success in improving adherence. Although methods are not yet available for routine use, providing information to guide individualized self management to the diabetic patients may enhance the medication adherence and clinical outcomes. Patients and providers need to actively and regularly discuss the goals of therapy and address concerns about adherence, attitudes, side effects and other matters of significance in achieving the individualized clinical outcomes.

The findings of this study will need to be reinforced and replicated with larger sample size and longer followup times to improve their external validity. Moreover, further studies are needed to confirm that interventions incorporating these components will result in increased and sustained patient adherence and, better yet, will improve outcomes.

\section{ACKNOWLEDGEMENTS}

We would like to thank the department of Pharmacy, Kathmandu University and Dhulikhel hospital, Kathmandu University Hospital for their support and cooperation during this study. A sincere thanks goes to all the patients who patiently got involved in this research.

\section{REFERENCES}

1. Danaei G, Finucane MM, Lu Y, Singh GM, Cowan MJ, Paciorek CJ et.al. National, regional, and global trends in fasting plasma glucose and diabetes prevalence since 1980: systematic analysis of health examination surveys and epidemiological studies with 370 countryyears and 2.7 million participants. Lancet. 2011; 378(9785):31-40. 
2. Brunton S, Gough S, Hicks D, Weng J, Moghissi E, Peyrot M et.al. A look into the future: improving diabetes care by 2015. Curr Med Res Opin. 2011; 27 Suppl 3: 65-72.

3. Annual Report 2004/ 2005, Department of Health Services, Nepal.

4. U.K. Prospective Diabetes Study (UKPDS) Group: Intensive bloodglucose control with sulfonylureas or insulin compared with conventional treatment and risk of complications in patients with type 2 diabetes (UKPDS 33). Lancet. 1998; 352:837-853.

5. Haynes RB, Taylor DW, Sackett DL. Compliance in health care. Baltimore: Md, Johns Hopkins University Press; 1979.

6. Haynes RB, Taylor DW, Sackett DL, Gibson ES, Bernholz CD, Mukherjee J. Can simple clinical measurements detect patient noncompliance? Hypertension 1980; 2: 757-764.

7. Kurtz SMS. Adherence to diabetes regimens: empirical status and clinical applications. Diabetes Education. 1990; 16:50 -56.

8. McDonald HP, Garg AX, Haynes RB. Interventions to enhance patient adherence to medication prescriptions: scientific review. JAMA 2002; 28: 2868-79.

9. Polonsky WH, Boswell SL, Edelman SV. Physician attributions concerning regimen adherence. Diabetes 1996; 45 Suppl 2:14.

10. American Diabetes Association. Diagnosis and classification of dia-betes mellitus: (Position Statement). Diabetes Care. 2012; 35 1: 64-71.

11. O'Connor PJ. Improving medication adherence. Arch Intern Med 2006; 166:1802-1804.

12. Shelly AV, Colleen JM, David BH, Scott BP, Jeffrey AJ, Lori RS. Assessing medication adherence among older persons in community settings. Can J Clin Pharmacol. 2005; 2 (1): 152-164.

13. Lars $O$ and Terrence B. Adherence to Medication. NEJM. 2005; 353(5):487-497.

14. Mukherjee S, SharmaSarkar B, Das KK, Bhattacharyya A, Deb A. Compliance to Anti-Diabetic Drugs: Observations from the Diabetic Clinic of a Medical College in Kolkata, India. Journal of Clinical and Diagnostic Research. 2013; 7(4): 661-665.

15. Dailey G, Kim MS, Lian JF. Patient compliance and persistence with antihyperglycemic drug regimens: evaluation of a Medicaid patient population with type 2 diabetes mellitus. Clin Ther. 2001; 23:13111320.

16. Karmacharya BM, Pitisuttithum P, Desakorn V, Dhitavat J, MaelA-Nantawat W et.al. MSc Thesis. Mahidol University, Bangkok; Thailand:2006.

17. Jenny J. Differences in Adaptation to Diabetes Between InsulinDependent and Non-Insulin Dependent Patients: Implications for Patient Education. Patient Education and Counseling. 1986; 8: 39-50.

18. A' IvarezGuisasola F, Tofe' Povedano S, Krishnarajah G, Lyu R, Mavros $P$ and Yin D. Hypoglycaemic symptoms, treatment satisfaction, adherence and their ssociations with glycaemic goal in patientswith type 2 diabetes mellitus: findings from the Real-Life Effectiveness and Care Patterns of Diabetes Management (RECAP-DM) Study. Diabetes, Obesity and Metabolism. 2008; 10 Suppl 1:25-32.

19. Cooper JK, Love DW, Raffoul PR. Intentional prescription nonadherence (noncompliance) by the elderly. J Am Geriatr Soc 1982; 30(5):329-33.
20. Davis S, Alonso MD. Hypoglycemia as a barrier to glycemic control. J Diabetes Complications. 2004; 18: 60-68.

21. Waller DG: Rational prescribing: the principles of drug selection and assessment of efficacy. Clin Med. 2005; 5:26-28.

22. Polonsky WH, Dudl RJ, Peterson M, Steffian G, Lees J, Hokai H. Depression in type 2 diabetes: links to health care utilization, self-care and medical markers. Diabetes. 2000; 49 Suppl 1:64.

23. Schafheutle EI, Hassell K, Noyce PR, Weiss MC. Access to medicines: cost as an influence on the views and behaviour of patients. Health Soc Care Community. 2002; 10:187-195.

24. Lawton J, Peal E, Parry O, Douglas M. Patients' perceptions and experiences of taking oral glucose lowering agents: a longitudinal qualitative study. Diabet Med 2008; 25:491 -495.

25. Peyrot M, Rubin RR, Lauritzen T, Snoek FJ, Matthews DR, Skovlund SE. Psychosocial problems and barriers to improved diabetes management: results of the Cross-National Diabetes Attitudes, Wishes and Needs (DAWN) Study. Diabet Med. 2005; 22:1379 -1385.

26. Mulye RR, Almeida N. Knowledge, Health Beliefs, Family Support, Patient Provider Interaction: A Comparative Study of Type 2 Diabetes Patients Higher in Adherence and Lower in Adherence to the Diabetes regimen. Int J Diab Dev Ctries. 2002; 22:51-60.

27. Claxton AJ, Cramer J, Pierce C. A systematic review of the associations between dose regimens and medication compliance. Clin Ther. 2001; 23:1296-1310.

28. Grant RW, Nicole GD, Daniel ES, James BM. Polypharmacy and Medication Adherence in Patients With Type 2 Diabetes. Diabetes Care. 2003; 26:1408-1412.

29. Lee R, Deborah A, Taira DA, ScD. Adherence to Oral Hypoglycemic Agents in Hawaii, Preventing Chronic Disease, Public Health Research, Practice, and Policy. 2005;2 (2):1

30. Schectman JM, Nadkarni MM, Voss JD. The association between diabetes metabolic control and drug adherence in an indigent population. Diabetes Care. 2002; 25:1015-1021.

31. Wagner EH, Grothaus LC, Sandhu N. Chronic care clinics for diabetes in primary care: a system-wide randomized trial. Diabetes Care. 2001; 24:695 -700.

32. Maronde RF, Chan LS, Larsen FJ, Strandberg LR, Laventurier MF, Sullivan SR. Underutilization of antihypertensive drugs and associated hospitalization. Med Care. 1989; 27:1159 -1166.

33. Kravitz RL, Hays, RD, Sherbourne CD, DiMatteo MR, Rogers WH, Ordway $L$ et.al. Recall of recommendations and adherence to advice among patients with chronic medical conditions. Arch Intern Med 1993; 153: 1869-1878.

34. Pascal IGU, Ofoedu JN, Uchenna NP, Nkwa AA and Uchamma GE. Blood Glucose Control and Medication Adherence Among Adult Type 2 Diabetic Nigerians Attending A Primary Care Clinic in Underresourced Environment of Eastern Nigeria. N Am J Med Sci. 2012; 4(7): 310-315

35. Loke SC, Jony M. Metabolic Control in Type 2 Diabetes Correlates Weakly with Patient Adherence to Oral hypoglycemic Treatment. Annals Academy of Medicine. 2008;37:15-20.

36. Diehl AK, Bauer RL, Sugarek NJ. Correlates of medication compliance in non-insulin-dependent diabetes mellitus. South Med J. 1987; 80:332 -335. 